\title{
Mestiçagem e perversão sexual em Gilberto Freyre e Arthur de Gobineau
}

\section{Miscigenation and sexual perversion in Gilberto Freyre and Arthur de Gobineau}

Alexandre Almeida Marcussi

Se nos brasis abunda / Fenipapo na bunda

Se somos todos uns / Octoruns, Que importa? É lá desgraça? / Essa história de raça, Raças más, raças boas / - Diz o Boas É coisa que passou / Com o franciú Gobineau. Pois o mal do mestiço / Não está nisso.

Manuel Bandeira, "Casa-grande \& senzala" (apud Freyre, 1984: XXXIII)

Alexandre Almeida Marcussi é doutorando em História Social na Faculdade de Filosofia, Letras e Ciências Humanas da USP, São Paulo, Brasil (alexandremarcussi@gmail.com).

Este artigo resultou de uma pesquisa que contou com o apoio financeiro da FAPESP e da CAPES.

Artigo recebido em 29 de junho e aprovado para publicação em 10 de setembro de 2013.

Est. Hist., Rio de Faneiro, vol. 26, no 52, p. 275-293, julho-dezembro de 2013. 


\section{Alexandre Almeida Marcussi}

A valorização da mestiçagem racial e cultural foi, sem dúvida, uma das mais importantes contribuições intelectuais trazidas por Gilberto Freyre em seu Casa-grande E senzala, de 1933 (Azevedo, 1962; Araújo, 1994; PallaresBurke, 2005, entre outros). Ao apontar a combinação das heranças de europeus, indígenas e africanos como um atributo positivo da nação, Freyre rejeitou as ideias hegemônicas no Brasil no final do século XIX e nas primeiras décadas do XX.

Até então, as discussões a respeito do problema da mestiçagem racial no Brasil baseavam-se no pressuposto fundamental da inferioridade das raças não brancas, em consonância com as hierarquias estabelecidas pelo pensamento racial oitocentista. De acordo com o médico maranhense Raimundo Nina Rodrigues, a mestiçagem entre brancos, negros e indígenas resultava em "um produto desequilibrado e de frágil resistência física e moral", caracterizado pela indolência, pela suscetibilidade a patologias diversas e pela tendência à criminalidade (Rodrigues, 2008: 1161). Na melhor das hipóteses, a mestiçagem era encarada como relativamente positiva com uma condição: desde que se tratasse do "branqueamento" da população negra e mulata devido ao cruzamento com imigrantes europeus, o que minimizaria o impacto negativo da herança africana, como sugeria João Batista Lacerda (Schwarcz, 1993; Skidmore, 1976).

Freyre, ao contrário, rejeitou as hierarquias entre as raças e encarou a mestiçagem como fator favorável em si, que teria dado origem a uma sociedade superior às suas matrizes originais, no seio da qual as contribuições das três raças fundadoras (índios, brancos e negros) se complementariam positivamente. $\mathrm{O}$ abandono das teses racialistas, sob influência da antropologia culturalista de Franz Boas, foi assinalado pelo próprio Freyre no prefácio à primeira edição de Casa-grande E'senzala: "Aprendi a considerar fundamental a diferença entre raça e cultura; a discriminar entre os efeitos de relações puramente genéticas e os de influências sociais, de herança cultural e de meio" (Freyre, 1984: LVII-LVIII). Contudo, é notória a ocorrência de argumentos de determinação biológica e racial na obra de Freyre, o que nos levaria a questionar a extensão de sua fidelidade ao culturalismo boasiano e investigar os vínculos que o ligam às matrizes do pensamento racialista.

Pretendo sugerir que, mais do que na linguagem racial, é na estrutura lógica de sua argumentação e, paradoxalmente, na própria teoria da mestiçagem que podemos reencontrar, em Freyre, paradigmas caros a algumas das teorias biológicas do século XIX. Para isso, depois de analisar brevemente o estatuto teórico da linguagem racial que aparece no texto de Freyre, pretendo comparar sua tese da mestiçagem com as ideias do francês Arthur de Gobineau, demonstrando vínculos profundos que os unem no seio de um complexo de pensamento e sensibilidade que transcende as teorias de ambos. 


\section{Mestiçagem e perversão sexual em Gilberto Freyre e Arthur de Gobineau}

\section{Linguagem racial e histórica em Casa-grande \& senzala}

É fato conhecido que o pensamento racial exerceu papel importante na formação de Gilberto Freyre, sobretudo por meio da influência de autores norte-americanos que defendiam políticas de eugenia nos EUA, como Madison Grant e Lothrop Stoddard, admirados pelo jovem Freyre, bem como por meio dos diálogos que ele mantinha com Oliveira Lima, defensor do branqueamento no Brasil (Pallares-Burke, 2005: 261-297). Entre o final da década de 1920 e o início dos anos 1930, porém, Freyre teria se afastado das teses racialistas para adotar uma perspectiva teórica relativista que marcou as análises de Casa-grande $\mathcal{E}$ senzala.

Apesar disso, a transição da determinação racial para a histórica não se realizou sem deixar ambiguidades e marcas sobre a obra freyreana. De fato, o ensaio alterna frequente e livremente entre argumentos de determinação racial e histórica. Para Antonio Candido, essa oscilação seria um dos aspectos da "ambiguidade dinâmica" que caracteriza a prosa freyreana (Candido, 1962: 120) e que torna tão difícil circunscrever com precisão as ideias sociológicas do ensaísta pernambucano. Luiz Costa Lima, em uma análise cuidadosa da retórica empregada em Casa-grande E senzala, evidenciou uma flutuação recorrente entre determinação racial, climática, cultural e econômica. Para ele, essa alternância teórica pouco rigorosa daria ao ensaio um tom mais oral do que propriamente científico, construindo uma narrativa mítica da história brasileira (Lima, 1989: 231-236). Não faltou quem buscasse compreender o sentido dessa flutuação teórica na trajetória intelectual do autor. Alfredo Boulos Júnior (2001) a interpretou como uma confusão conceitual, que Freyre tentou encobrir com o tratamento estético de sua prosa. Pallares-Burke (2005: 326), por sua vez, a explicou como um sintoma das influências antagônicas na formação intelectual de Freyre, bem como de sua rejeição ainda muito recente das teses racialistas.

É preciso esclarecer que as constantes referências à herança biológica não chegam a ser conceitualmente contraditórias com os argumentos de determinação histórica e cultural de que Freyre se vale majoritariamente. Isso porque, em primeiro lugar, as raças são tratadas frequentemente como metonímias para a totalidade das culturas e/ou formações sociais que representam, cujas características, na maior parte das vezes, não são explicadas pelo recurso à biologia, mas sim à história. Além disso, Freyre empregava uma acepção neolamarckiana de raça (Araújo, 1994: 37), a partir da qual as influências do meio seriam transmitidas à descendência, num processo de adaptação que acabaria por transformar a herança genética (Freyre, 1984: 292-4). O fato de ele citar a transmissão hereditária de condicionamentos comportamentais sugere que, em sua concepção, o meio não se limitava ao clima, mas podia ser considerado de forma mais lata, 


\section{Alexandre Almeida Marcussi}

compreendendo também a história e a cultura. Nesse sentido, as influências culturais e históricas sobre um povo poderiam se converter, eventualmente, em características da raça.

Curiosamente, Freyre citou a autoridade científica de Franz Boas para respaldar essa concepção. Entre 1909 e 1912, Boas realizara uma pesquisa de antropologia física em comunidades de imigrantes norte-americanos, chegando à conclusão de que os tipos raciais seriam portadores de uma espécie de plasticidade, podendo manifestar características fenotípicas distintas de acordo com o ambiente (Boas, 1982: 60-75). Apesar de o antropólogo ter desautorizado expressamente a hipótese de que essa plasticidade se traduzisse em uma transmissão dos caracteres adquiridos às próximas gerações (base de uma teoria neolamarckiana), foi exatamente essa a ideia que Freyre inferiu de seu estudo. Com isso, afirmou um conceito de raça que, ao menos em parte, se confunde com o de cultura a partir de sua própria definição, dificultando que se separem as determinações estritamente biológicas das culturais e sociais. Para Freyre, as duas linguagens (a racial e a histórica) não se apresentavam como antagônicas; antes, reforçavam-se mutuamente.

As confluências mais significativas entre a obra freyreana e o pensamento racialista não podem, portanto, ser encontradas nos argumentos de determinação biológica, que figuram apenas marginalmente em Casa-grande E senzala $\mathrm{e}$ se confundem com a determinação cultural e histórica da qual não podem ser separados. Sob outro ângulo, porém, essa oscilação en tre as linguagens da raça e da cultura sugere a existência de um terreno teórico movediço, sobre o qual tanto o relativismo cultural quan to o racialismo se moviam, o que permitiu que Freyre os combinasse livremente em sua obra.

As matrizes intelectuais do racialismo remontam às críticas dirigidas, entre os séculos XVIII e XIX, ao pensamento ilustrado de natureza igualitária. Um de seus antecedentes na França pode ser encontrado no pensamento germanista do século XVIII, que atribuiu à ascendência genealógica germânica da nobreza francesa suas qualidades distintivas, repudiando a repartição de seus privilégios com grupos sociais de estirpe supostamente inferior (Gahyva, 2011: 503-506). Outra fonte das teorias raciais remontava ao pensamento romântico alemão, em especial na figura de Johann von Herder, que criticava o universalismo ilustrado com base na ideia de que o espírito humano estaria configurado em formas particulares, de natureza étnica ou nacional. ${ }^{1}$ As teses românticas tinham como corolário a distinção entre uma "civilização" superficial, artificialmente universal, e uma "cultura" profunda e autêntica, característica de cada povo (Elias, 1990: 9-64). O racialismo científico do século XIX ressignificou essas duas correntes de pensamento, creditando à herança biológica (não mais à história genealógica ou à cultura nacional) o fundamento das diferenças entre os grupos sociais. 


\section{Mestiçagem e perversão sexual em Gilberto Freyre e Arthur de Gobineau}

As teorias racialistas supunham que as raças fossem qualitativamente distintas entre si, e que os comportamentos dos indivíduos seriam determinados pelas capacidades, limites e tendências particulares de sua raça, donde se explicaria a heterogeneidade dos hábitos e sociedades humanas. Assim, a raça fornecia uma explicação em termos biológicos para a diversidade dos povos e costumes, podendo ser incluída em uma linhagem de pensamento que George Stocking Jr. denominou "diversitária", ou seja, preocupada fundamentalmente com a explicação das diferenças entre os homens. $\mathrm{O}$ autor aponta a existência de um paradoxal paralelo, do ponto de vista lógico, entre essa natureza diversitária do racialismo e as teorias culturalistas de Franz Boas, notório crítico do racismo norte-americano. Boas rejeitava a determinação racial, mas aceitava a diversidade fundamental dos povos e costumes, e propunha fundar essa diversidade não na raça, mas na cultura (de volta aos termos românticos do problema). Ou seja, Boas mantinha, na raiz, um pensamento diversitário (análogo ao das teorias racialistas), sendo que a cultura - à semelhança da raça - explicaria comportamentos, ideias, crenças, costumes e percursos históricos divergentes (Stocking Jr., 1982: 214).

Reflexões de linhagem diversitária, na medida em que pressupõem a existência de características divergentes entre os grupos humanos, precisam elaborar explicações para os processos de intercâmbios e interações entre coletividades que, em teoria, seriam fundamentalmente distintas entre si. Por isso mesmo, o problema da mestiçagem tornou-se importante tanto para o pensamento racialista quanto para a antropologia culturalista. No primeiro caso, a reflexão se voltou para a viabilidade da miscigenação biológica; no segundo, girou em torno dos conceitos de aculturação e sincretismo. Não será surpreendente, portanto, reencontrar na teoria da mestiçagem de Freyre uma concepção que já havia sido adiantada por Gobineau a respeito do cruzamento entre raças.

\section{Perversão e equilíbrio}

É conhecida a representação que Freyre faz das relações escravistas no Brasil como relativamente harmônicas, marcadas pela aproximação e por uma afeição mútua entre senhores e escravos. A ideia de uma "democracia racial" no Brasil, segundo a qual não haveria atritos severos no país entre brancos e negros, antecede a obra de Freyre e encontra suas raízes na própria ideologia senhorial que vigia antes da abolição da escravidão, tendo sido denunciada em 1883 pelo abolicionista Joaquim Nabuco (Nabuco, 2012: 97). Nas primeiras décadas do século XX, o mito da democracia racial era sistematicamente empregado pelas elites tradicionais como forma de preservar um padrão patriarcal 


\section{Alexandre Almeida Marcussi}

de relações raciais na sociedade urbana da Primeira República (Fernandes, 1965, v. I: 194-210).

Casa-grande E senzala insiste na ideia de que todas as relações mais essenciais da formação social brasileira estariam atravessadas por diversos antagonismos, o mais importante e determinante deles sendo o antagonismo entre senhor e escravo. Contudo, a família patriarcal teria sua estabilidade fundada no fato de que ela oferecia uma série de espaços de confraternização entre seus elementos opostos, nos quais os choques seriam amortecidos e os antagonismos se equilibrariam, o que teria engendrado um ambiente de mobilidade social mais intensa e de contato mais harmônico, democrático e fluido entre os extremos sociais e raciais.

De todos os espaços de aproximação entre os opostos, o mais decisivo na obra de Freyre é, sem dúvida alguma, a confraternização sexual. Verdadeira obsessão do autor, pode ser considerada o aspecto dominante do retrato que ele elabora das relações interraciais no Brasil, localizadas no ambiente de "intoxicação sexual" da casa-grande. A relação sexual entre homens brancos e mulheres negras e índias é encarada, inclusive, como um dos sustentáculos da família patriarcal e, por extensão, da sociedade brasileira, já que por meio dela é que o colono português teria dado conta de ocupar a terra com uma prole mestiça e garantido, assim, o sucesso do empreendimento colonial. Para Ricardo Benzaquen de Araújo (1994), a casa-grande freyreana se caracteriza por um ethos da hybris - ou seja, do excesso desmedido - e por uma aristocracia carnavalesca que, ao invés de rejeitar os apetites e impulsos corporais e a proximidade com as classes baixas, potencializaria sua aproximação em relação a elas por meio dos contatos sexuais.

Isso não significa, no entanto, que a posição de Freyre coincida com a ideologia de uma escravidão branda, sem violência ou dominação. Pelo contrário, a convivência próxima e mesmo a intoxicação sexual também teriam dado ensejo a violências reiteradas e sistemáticas, constitutivas da vida cotidiana na família patriarcal. São eloquentes os relatos de Freyre a respeito de abusos sexuais e da extrema violência exercida sobre os escravos, entre os quais seleciono um excerto especialmente brutal:

Não são dois nem três, porém muitos os casos de crueldade de senhoras de engenho contra escravos inermes. Sinhá-moças que mandavam arrancar os olhos de mucamas bonitas e trazê-los à presença do marido, à hora da sobremesa, dentro da compoteira de doce e boiando em sangue ainda fresco. Baronesas já de idade que por ciúme ou despeito mandavam vender mulatinhas de quinze anos a velhos libertinos. Outras que espatifavam a salto de botina dentaduras de escravas; ou 


\section{Mestiçagem e perversão sexual em Gilberto Freyre e Arthur de Gobineau}

mandavam-lhes cortar os peitos, arrancar as unhas, queimar a cara ou as orelhas. Toda uma série de judiarias. (Freyre, 1984: 337)

Freyre reconhece que essa proximidade entre os opostos nem sempre se realizava em um ambiente de voluntarismo recíproco e que, se ela gerava experiências positivas de afeição e respeito, também engendrava experiências negativas de violência e indignidade, sendo responsável tanto pelas virtudes quanto pelos vícios da sociedade brasileira. A questão, então, é entender como Freyre resolve o problema representado pela tentativa de fundar uma ordem social estável num solo de excessos reiterados. Que tipo de cimento seria capaz de atar as partes multiformes de uma sociedade construída em tal regime de (des)ordenamento? Para Araújo, a resposta teria de ser buscada em um modelo de sociabilidade contraposto ao da família patriarcal e representado pelos quilombos e mocambos, caracterizados por uma afetividade não mais excessiva, mas contida, fraterna. A contraparte senhorial desse regime de sociabilidade, constituindo um possível esteio de estabilidade da casa-grande, poderia ser encontrada nas mulheres brancas, que saberiam conjugar de forma harmônica (e não mais excessiva e violenta) os antagonismos das culturas que formaram a colonização, como se verificaria nos comentários de Freyre a respeito da culinária das sinhás (Araújo, 1994: 165-181).

Contudo, podemos nos questionar a respeito da viabilidade da ordem fraterna e feminina que caracterizaria os mocambos como modelo social alternativo ao patriarcal, já que Freyre é enfático ao dizer que, sem a escravidão e sem esse excessivo patriarcalismo masculino, não seria possível realizar a colonização do Brasil, a ocupação do território e a produção de riquezas. Também a representação da mulher é bastante ambígua na obra de Freyre: se, por um lado, ele enfatiza sua tendência à estabilidade e ao pensamento prático (o que reforçaria essa maneira calma de conjugar os extremos de que fala Araújo), por outro, ressalta os excessos de sadismo das sinhás, como no excerto transcrito há pouco. Mais que isso: o pensamento prático das mulheres e sua tendência à estabilidade não seriam apenas tendências naturais e biológicas do sexo feminino e opostas ao viril regime patriarcal, mas também traços condicionados por ele. A tendência das mulheres ao recato, à delicadeza e à passividade seria o resultado de uma reclusão que relegava o sexo feminino à casa-grande e facultava aos homens o acesso à esfera pública e ao exercício do poder e do mando (Bocayuva, 2001; Westphalen, 2001). No limite, a tenra fraternidade feminina não deixaria de ser um subproduto dessa excessiva família patriarcal, não podendo ser pensada como alternativa a ela.

Há, em Casa-grande E̛ senzala, um elemento interno aos excessos senhoriais que garantiria a união, senão harmônica, pelo menos estável dos antagonis- 


\section{Alexandre Almeida Marcussi}

mos sociais e raciais que compõem a sociedade brasileira. Se é verdade, como afirma Bocayuva, que a linguagem do gênero é o grande diacrítico da obra de Freyre para se referir às relações sociais, estabelecendo o masculino como polo dominante e o feminino como polo dominado, então é coerente que o princípio de estabilidade social seja encontrado justamente no âmago da relação sexual, no perverso regime de afetividade criado pela sexualidade excessiva e ambígua do patriarcalismo. Também aí reinariam a violência e os abusos senhoriais: para Freyre, é da natureza mesma do escravismo que ele engendre a depravação sexual, por conta da disponibilidade sexual das escravas (na ótica de seus senhores, obviamente) e da necessidade de gerar uma prole, que a classe senhorial satisfazia incentivando as relações sexuais com as escravas. Nem sempre, como se pode supor, essas relações eram voluntárias:

$\mathrm{O}$ intercurso sexual entre o conquistador europeu e a mulher índia [...] verificou-se - o que depois se tornaria extensivo às relações dos senhores com as escravas negras - em circunstâncias desfavoráveis à mulher. Uma espécie de sadismo do branco e de masoquismo da índia ou da negra terá predominado nas relações sexuais como nas sociais do europeu com as mulheres das raças submetidas ao seu domínio. O furor femeeiro do português se terá exercido sobre vítimas nem sempre confraternizantes no gozo; ainda que se saiba de casos de pura confraternização do sadismo do conquistador branco com o masoquismo da mulher indígena ou da negra. Isto quanto ao sadismo de homem para mulher - não raro precedido pelo de senhor para muleque. (Freyre, 1984: 50 , grifos meus)

A violência genética e fundadora das interações entre dominantes (homens brancos) e dominados (mulheres de cor) teria engendrado um regime de afetividade assimétrico, marcado ao mesmo tempo pela violência e pelo gozo. Por meio de interações reiteradamente violentas, o senhor branco teria se tornado sádico, e seus dominados, masoquistas, passando ambos a procurar o prazer no exercício da violência: uns na posição do dominador, outros na posição do dominado. É como se essa cena primordial escravista, na fundação da nação brasileira, tivesse gerado uma espécie de protocolo afetivo, estabelecendo papéis a serem repetidamente ocupados, recompensados com o gozo de ambas as partes. A relação sexual escravista, no limite, daria origem a um regime de perversões afetivas que se encarregaria de manter a ordem social sempre estável, reproduzindo papéis de dominação e subjugação afetivamente significativos e, portanto, reiterados de forma relativamente voluntária. 


\section{Mestiçagem e perversão sexual em Gilberto Freyre e Arthur de Gobineau}

Como grifei no excerto transcrito acima, essa afetividade perversa e assimétrica dominaria as relações sexuais bem como as sociais, e se estenderia para outras interações além daquelas entre homens brancos e mulheres de cor. Isso é perfeitamente condizente com o fato, já ressaltado, de que Freyre usa a linguagem do gênero para significar as relações de dominação em geral. Já a primeira extensão do sadismo do senhor ocorre em relação ao muleque (o escravo menino), transformado no masoquista da relação. E estende-se quase como em cadeia por todo o tecido social, oferecendo um modelo explicativo global para as relações sociais, culturais e até políticas:

Mas esse sadismo de senhor e o correspondente masoquismo de escravo, excedendo a esfera da vida sexual, têm-se feito sentir através da nossa formação, em campo mais largo: social e político. Cremos surpreendê-lo em nossa vida política, onde o mandonismo tem sempre encontrado vítimas em quem exercer-se com requintes às vezes sádicos; certas vezes deixando até nostalgias logo transformadas em cultos cívicos, como o do chamado marechal-de-ferro. [...] Mesmo em sinceras expressões individuais - não de todo invulgares nesta espécie de Rússia americana que é o Brasil - de mística revolucionária, de messianismo, de identificação do redentor com a massa a redimir pelo sacrifício de vida ou de liberdade pessoal, sente-se o laivo ou o resíduo masoquista: menos a vontade de reformar ou corrigir determinados vícios de organização política ou econômica que o puro gosto de sofrer, de ser vítima, ou de sacrificar-se.

Por outro lado, a tradição conservadora no Brasil sempre se tem sustentado do sadismo do mando, disfarçado em "princípio de Autoridade" ou "defesa da Ordem". Entre essas duas místicas - a da Ordem e a da Liberdade, a da Autoridade e a da Democracia - é que se vem equilibrando entre nós a vida política, precocemente saída do regime de senhores e escravos. Na verdade, o equilíbrio continua a ser entre as realidades tradicionais e profundas: sadistas e masoquistas, senhores e escravos, doutores e analfabetos, indivíduos de cultura predominantemente europeia e outros de cultura principalmente africana ou ameríndia. (Idem: 51-52)

Nesse ponto, pode-se surpreender a perversão afetiva como o mais sólido cimento das relações sociais na sociedade brasileira. A estabilidade não estaria dada por uma afetividade tenra, fraterna, exterior a essas relações excessivas de violência e gozo na casa-grande, mas sim pela afetividade perversa que se 


\section{Alexandre Almeida Marcussi}

forma no interior delas e que produz dominadores sádicos e dominados masoquistas.

Trata-se, na realidade, de uma representação ainda mais perversa do que a "dominação adocicada" idealizada pela ideia de democracia racial: ela sugere que a subjugação do dominado seria pelo menos parcialmente voluntária, já que ele seria um masoquista. Dominante e dominado se encontrariam num suposto gozo da própria violência, muito mais difícil de ser rompida porque afetivamente recompensadora, ainda que de forma perversa. Luiz Costa Lima argumentou que a narrativa de Casa-grande $\mathcal{E}$ senzala mitifica uma curiosa "democracia" que, por se limitar ao âmbito privado, pode ser reafirmada como valor a despeito da prática reiterada de relações políticas e econômicas assimétricas na esfera pública (Lima, 1889). Parece-me, contudo, que a clivagem entre público e privado não é tão acentuada: a singular "democracia" freyreana, na esfera privada como também na pública (constituídas de forma especular), é transpassada por uma assimetria constitutiva que nunca se desfaz completamente, e que é aceita voluntariamente devido à perversão de ambas as partes, dominados e dominadores.

\section{Sadismo e civilização em Gobineau}

Em Casa-grande Ésenzala, o recurso à perversão sexual como fator de estabilidade da estrutura social tem como objetivo explicar a aproximação entre senhores e escravos, brancos e negros, dois grupos divididos por profundas diferenças sociais e culturais. A sociabilidade compulsória da casa-grande garantiria a interação entre esses dois conjuntos que, presume-se, permaneceriam separados em outras situações mais voluntárias. É verdade, por um lado, que Freyre não atribui a separação entre os dois grupos apenas aos fatores raciais ou culturais, já que ela seria condicionada pelo regime de escravidão. Por outro lado, é impossível deixar de reconhecer que Freyre naturalizava, em certa medida, essa dicotomia racial ao se referir às "tradições diversas, ou antes, antagônicas, de cultura" (Freyre, 1984: 52) que o patriarcalismo teria reunido. No deslizamento entre determinação econômica, cultural e racial que é característico da prosa de Freyre, a distinção entre os grupos é atribuída simultaneamente a todos esses domínios. Qualquer que seja a natureza da diferença, o sadomasoquismo é a única forma de sociabilidade que reúne os diferentes em Casa-grande E senzala.

Encontramos tese surpreendentemente semelhante no Ensaio sobre a desigualdade das raças humanas, publicado pelo francês Joseph Arthur de Gobineau nos anos de 1853 e 1855. Dividida em seis "livros" reunidos em quatro volumes, a obra apresenta uma teoria geral da história da humanidade analisada sob o critério da raça e da mestiçagem racial. O primeiro livro, que nos interessa mais par- 


\section{Mestiçagem e perversão sexual em Gilberto Freyre e Arthur de Gobineau}

ticularmente aqui, é dedicado a uma exposição teórica a respeito das raças humanas e dos processos de desenvolvimento e decadência das civilizações, sendo que os cinco livros restantes apresentam análises históricas nas quais são aplicados e corroborados os conceitos teóricos.

Gobineau foi amplamente condenado na segunda metade do século XX por uma lenda que lhe atribuiu a paternidade do racismo científico oitocentista. Contudo, sua obra teve parca recepção antes do final do século XIX; ademais, ela apenas sistematizou teorias raciais que já eram conhecidas à sua época, não tendo sido tão determinante para o desenvolvimento das teses racialistas (Boissel, 1967; Poliakov, 1975: 217). Pode-se considerar que sua particularidade foi a de ter elevado a mestiçagem racial à categoria central de sua teoria da história. Havia antecedentes para essa ideia, já que Victor Courtet de l'Isle já se referia, na década de 1830, às misturas de sangues como um dos fatores essenciais da história humana. Da mesma forma, Gustav Klemm, em 1843, referia-se à concretização da completude do homem por meio do processo de mistura de raças "ativas/masculinas" e "passivas/femininas" (Poliakov, 1975: 212, 237). Foi Gobineau, porém, quem deu à mestiçagem racial um tratamento sistemático, elegendo-a como critério fundamental de inteligibilidade da história humana.

Gobineau englobou as reflexões de seu tempo sobre a raça no seio de uma visão de mundo pessimista, intimamente ligada a um pensamento aristocrático crítico da modernidade republicana e democrática (Boissel, 1967: 55-61). Sua visão da mestiçagem era essencialmente ambígua. Por um lado, ela redundava na degeneração da prole mestiça, incongruentemente composta de caracteres conflitantes e privada das melhores qualidades de sua ascendência. Foi como teórico da degeneração que ele foi recebido no Brasil, tendo sido amplamente invocado por Nina Rodrigues para sustentar as teses sobre o caráter patológico da população brasileira mestiça. Sua popularidade no Brasil foi provavelmente amplificada pelo fato de que ele atuou como ministro da França na corte de D. Pedro II e viveu no Rio de Janeiro entre 1869 e 1870, tendo emitido juízos negativos a respeito da população mestiça do país (Raeders, 1988).

No entanto, Gobineau não encarava a mestiçagem racial sob um prisma exclusivamente negativo. Antes, ela constituiria a própria condição de origem de toda civilização. Isso porque, mais que uma teoria da mestiçagem, o Ensaio sobre a desigualdade das raças humanas propunha-se oferecer uma teoria do surgimento e da decadência das civilizações, entendidas como resultados de um processo ao mesmo tempo político (o "adocicamento" dos costumes) e cultural (as realizações intelectuais e estéticas).

Para Gobineau, nem todos os povos podem se civilizar: na verdade, a raça branca, sendo aquela dotada de maior grau de capacidade física, intelectual e moral, seria a única capaz de criar sociedades civilizadas (Gobineau, 1853: 


\section{Alexandre Almeida Marcussi}

352-354). Contudo, para que esse processo civilizador se efetivasse, era imprescindível que a raça dominante branca acabasse se misturando, em maior ou menor grau, a raças inferiores amarelas ou negras. Uma coletividade racialmente homogênea que se mantivesse isolada e pura não passaria de uma tribo. Para que ela se transformasse num Estado e organizasse uma economia de grandes proporções, era imperativo que se expandisse para territórios adjacentes e, nesse processo, englobasse e subjugasse povos mais fracos. Com o tempo, a convivência territorial e a interdependência econômica entre os dois grupos raciais levariam a inevitáveis cruzamentos e, consequentemente, ao surgimento de um novo povo mestiço:

Algumas outras [tribos], mais imaginativas e enérgicas, são capazes de compreender algo além da simples pilhagem; elas conquistam uma vasta terra e tomam como propriedade sua não apenas os seus habitantes, mas juntamente o solo. Forma-se então uma verdadeira nação. Frequentemente, durante um tempo, as duas raças continuam a viver lado a lado sem se misturar; no entanto, como elas se tornaram indispensáveis uma à outra, como se estabeleceu uma duradoura comunhão de trabalho e interesses, como os ressentimentos da conquista e o orgulho se enfraqueceram, enquanto os que estão por baixo tendem naturalmente a se elevar ao nível de seus mestres, estes encontram mil motivos para tolerar e às vezes até para servir a esta tendência, a mistura do sangue acaba ocorrendo, e os homens das duas origens, não mais pertencendo a tribos distintas, confundem-se cada vez mais. (Idem: $44-45)^{2}$

Sendo assim, a mestiçagem seria o resultado e, ao mesmo tempo, um requisito para a formação de uma sociedade civilizada. Ela se intensificaria à medida que essa sociedade crescesse, pois a prosperidade da nação e sua expansão militar fariam com que ela absorvesse um número ainda maior de povos de composição racial distinta. Como resultado, o caráter racial do grupo dominante seria cada vez mais alterado.

Até certo ponto, as mestiçagens poderiam resultar em um produto positivo. Gobineau estabeleceu uma sucessão de tipos raciais puros e mestiços, possuindo diferentes graus de viabilidade, desde a diferenciação original do gênero humano até o presente. $\mathrm{O}$ tempo da humanidade estaria dividido em duas partes qualitativamente distintas: a primeira começaria com a criação de Adão por Deus, enquanto a segunda teria sido inaugurada pelas primeiras evidências históricas das civilizações antigas. Para Gobineau, a força da natureza se fazia sentir de forma muito mais violenta sobre os homens e sobre a Terra na primeira era; 
sob sua influência, a humanidade, apesar de possuir uma origem comum, teria se diferenciado para se adaptar às diferentes condições naturais. Primeiro teria havido a formação dos tipos secundários (brancos, negros e amarelos), seguida de um processo continuado de diferenciação e adaptação ambiental que teria levado à subdivisão das grandes raças nos tipos terciários, variações ain da isentas de misturas raciais na maior parte dos casos (Idem: 237-251).

É com a aurora das primeiras civilizações que Gobineu identifica os tipos quaternários, surgidos "do casamento de duas grandes variedades" terciárias (Idem: 252) por ocasião do processo de formação de civilizações. Esse casamento podia ser fecundo em algumas circunstâncias. Em primeiro lugar, o cruzamento entre tipos mais próximos tenderia a gerar misturas mais coerentes. Em segundo lugar, quando um número restrito de tipos (de preferência, apenas dois) se misturava de forma constante durante um longo período de tempo, os elementos díspares poderiam originar uma síntese coesa, gerando uma fusão mais completa, o que Gobineau chama de "misturas perfeitas" (Idem: 358).

No entanto, como vimos, a tendência de qualquer civilização em expansão é absorver um número cada vez maior de povos e raças, e as misturas entre elementos díspares tornam-se, então, cada vez mais difíceis de serem harmonizadas:

Logo que outros elementos vêm se juntar a uma criação desse gênero [uma mistura perfeita], a dificuldade de harmonizar o todo cria a anarquia, e [...] resta ainda o infortúnio de que as misturas não se interrompem, de que os homens medíocres, formados em detrimento de tudo o que era grande, se unem a novas mediocridades, e de que, desses casamentos, cada vez mais aviltados, nasce uma confusão que, semelhante àquela de Babel, conduz à mais completa impotência e leva as sociedades ao nada para o qual não há remédio. (Idem: 358-359)

Eis aí o processo que Gobineau denominava degeneração, que consiste na perda das qualidades iniciais que levaram determinado povo à sua ascensão, e que deriva da adulteração de sua tipicidade étnica (Idem: 39-40). Assim, a mesma mestiçagem que havia sido a causa e origem de sua grandeza acaba se tornando também, ambiguamente, a fonte de sua decadência.

Helga Gahyva argumentou que a teoria da degeneração de Gobineau reatualizava, em linguagem biológica, o pessimismo e a nostalgia da aristocracia francesa setecentista. Nesse sentido, a separação em três raças (branca, amarela e negra) poderia ser lida como metáfora da divisão da sociedade francesa do Antigo Regime em três classes (nobreza, burguesia e campesinato, respectivamente), e a degeneração, conduzindo à homogeneidade racial seria uma metáfora da re- 


\section{Alexandre Almeida Marcussi}

pública democrática e igualitária do século XIX, sob a ótica de uma aristocracia alienada do poder político. Para a autora, o ensaio teria uma concepção apenas superficialmente biológica, sendo o processo histórico a sua chave de entendimento (Gahyva, 2011). Contudo, a biologia a que recorre Gobineau naturaliza o devir histórico e transfere o foco do processo político da Revolução para o fato biológico da mestiçagem e do cruzamento racial, produzindo um rendimento teórico muito distinto e sendo alvo de uma recepção bastante diferente. É essa dimensão do ensaio que mais nos interessa na comparação com Freyre. Para aprofundá-la, cumpre entender de que forma Gobineau descreve biologicamente a mestiçagem.

Para o ensaísta francês, cada raça seria portadora de princípios físicos, morais e intelectuais incompatíveis com as outras, de modo que haveria entre os membros de uma raça uma natural aversão ao cruzamento com as demais, uma "lei de repulsão" que impediria as misturas necessárias ao surgimento da civilização. As raças inferiores sucumbiriam a essa natural repulsão, enquanto as superiores, movidas por uma "lei de atração" contrária a ela, seriam capazes de superá-la e construir grandes sociedades:

Sinto-me no direito de concluir [...] que a humanidade experimenta, em todos os seus ramos, uma repulsão secreta por cruzamentos; que, em muitos desses ramos, essa repulsão é invencível; que, em outros, ela é domesticada apenas até certo ponto; que aqueles, enfim, que se livram mais completamente do jugo dessa ideia não podem, contudo, se desvencilhar dela de tal forma que não restem pelo menos alguns traços: estes últimos formam tudo o que é civilizável em nossa espécie.

Assim, o gênero humano se encontra submetido a duas leis, uma de repulsão, outra de atração, agindo em diferentes graus sobre as diversas raças; duas leis, das quais a primeira só é respeitada por aquelas raças que nunca se elevarão acima dos aperfeiçoamentos mais elementares da vida tribal, enquanto a segunda, pelo contrário, reina com tanto maior domínio quanto mais as famílias étnicas sobre as quais ela se exerce são suscetíveis de desenvolvimentos. (Gobineau, 1853: 47-48)

É na forma como se processam os cruzamentos raciais, sob a influência simultânea da "lei de repulsão" e da "lei de atração", que encontramos as confluências entre Gobineau e Freyre em direção a um mesmo regime de perversão erótica. Ao contrário do que ocorre em relação ao ensaísta pernambucano, explícito no tom erótico de sua prosa, a sexualidade está apenas presumida no Ensaio 
sobre a desigualdade das raças humanas. Nem por isso ela é menos importante para a dimensão biológica do seu argumento, devendo ser buscada nas entrelinhas de sua teoria da mestiçagem.

Como argumentou Robert Young (1995: 109-117), a teoria gobiniana pressupõe, necessariamente, o estabelecimento de relações sexuais não consensuais entre raças brancas superiores e raças escuras subjugadas, as quais, demasiadamente dominadas pela "lei da repulsão", precisariam ser forçadas ao cruzamento. À atração sentida pelas raças superiores corresponderia necessariamente a aversão experimentada pelas raças inferiores, transformando o intercurso fundante da civilização em uma implícita cena de violência sexual, condizente com o cenário de conquista militar esboçado por Gobineau. A "atração" dos brancos, na medida em que se exerce sobre raças dominadas pela "repulsão", pode então ser entendida como um impulso sádico. Uma tal teoria, que postula a formação da civilização por meio de um sadismo dos brancos, assemelha-se notavelmente às ideias de Freyre, para quem a civilização brasileira teria sido constituída por meio de relações sexuais compulsórias nas quais os brancos assumiriam papeis sádicos reiterados.

Algumas diferenças importantes se impõem. Para Gobineau, a consequência desse sadismo seria ambígua: num primeiro momento, o estabelecimento e a expansão da civilização; já na sequência, e por sua prática reiterada, a degeneração e a decadência universais. Um resultado positivo seria seguido, necessariamente, por um negativo, desdobrando diacronicamente a ambiguidade da mestiçagem. Para Freyre, em contraste, positividade e negatividade se apresentariam simultaneamente numa sociedade em que a violência e a harmonia se confundem de forma inextricável, sintetizando uma peculiar "democracia" que o autor encara com complacência. Se é possível afirmar que ambos os autores fundam o surgimento da civilização em uma cena sadomasoquista, a distribuição dos papéis difere. Para Freyre, masoquistas são apenas as negras e índias, o que garante a continuada dominação dos brancos e a estabilidade indefinida da sociedade patriarcal. Já para Gobineau, o branco transforma-se metaforicamente em masoquista, ao iniciar o processo de degeneração de sua própria raça. Por isso mesmo, enquanto Gobineau apresenta um modelo conceitual da decadência, Freyre oferece uma teoria da harmonia e do "equilíbrio de antagonismos", que muito seduziu seus leitores a despeito de suas perversões implícitas.

\section{Conclusão}

O paralelo entre as ideias de Freyre e Gobineau a respeito do vínculo entre mestiçagem e perversão sexual não tem como objetivo comprovar uma in- 


\section{Alexandre Almeida Marcussi}

fluência direta do ensaísta francês sobre o pernambucano. Apesar de Gobineau ser bem conhecido no Brasil, não consta da extensa lista de referências bibliográficas de Casa-grande E senzala. Quero antes sugerir que as ideias dos dois autores, a despeito dos muitos afastamentos, moviam-se sobre um mesmo terreno compartilhado, uma mesma episteme que conduzia à inesperada emergência de soluções teóricas convergentes mesmo em autores frontalmente contrapostos. ${ }^{3}$

A importância do pensamento racial (e especialmente das teorias da degeneração dos mestiços) para a formação de Freyre já foi ressaltada, e vimos como a determinação racial é um elemento importante, embora secundário, de suas análises sobre a sociedade brasileira. Contudo, a persistência de um esquema teórico subjacente semelhante ao de Gobineau testemunha um vínculo ainda mais profundo do que aquele que se encontra na linguagem biológica. Tanto em Gobineau quanto em Freyre, a violência sexual como possibilidade de uma mestiçagem ordenada (que conduz à emergência histórica de civilizações, nos dois casos) tem um mesmo papel na economia explicativa: justificar de que maneira dois grupos caracterizados como antagônicos poderiam se misturar reiteradamente.

A violência sexual e o sadismo do conquistador só se justificam pelo caráter impensável de uma interação horizontal e voluntária entre os grupos em contato, já que estes seriam supostamente tão diferentes entre si que apenas a sociabilidade compulsória explicaria adequadamente sua interação continuada e estável. Em Gobineau, a diferença entre os grupos se encontra plenamente naturalizada pela biologia; em Freyre, por outro lado, ela é simultaneamente justificada por critérios econômicos, culturais e raciais alternantes. Brancos e negros se distinguiriam, naturalmente, pela sua raça e cultura, mas também pela fronteira imposta pelo escravismo. Ainda assim, é eloquente que em nenhum momento de Casa-grande $\mathcal{E}$ senzala Freyre tenha sequer imaginado a possibilidade de interação entre brancos e negros fora da sociabilidade perversa da casa-grande.

O que importa destacar é o fato de que ambas as teorias compartilham um pressuposto fundamental: a particularidade irredutível e até antagônica de grupos humanos definidos em termos ora raciais, ora históricos. Ambas, em suma, alicerçavam-se em uma reflexão sobre a diferença. Subjazendo intacta, em nível profundo, tanto em um dos teóricos do racialismo quanto em um dos mais notáveis introdutores do relativismo cultural no Brasil, essa premissa comum dá relevância à perturbadora hipótese de Stocking Jr. de que o pensamento racial e a antropologia culturalista fariam parte de uma mesma linhagem "diversitária" de pensamento. Diante disso, cabe atentar para os riscos implícitos nos projetos intelectuais calcados na rejeição da premissa da igualdade do gênero humano e na caracterização das coletividades sociais em termos exclusivamente particulares - seja essa particularidade baseada ou não na raça como critério explicativo. 


\section{Mestiçagem e perversão sexual em Gilberto Freyre e Arthur de Gobineau}

Notas

1. Isso não significa que os intelectuais do romantismo alemão tenham postulado hierarquias raciais. Para eles, as particularidades que distinguiam as sociedades umas das outras radicavam no campo espiritual, $\mathrm{e}$ não na biologia. A codificação biológica das particularidades humanas foi realizada pelas teorias racialistas desenvolvidas em grande medida durante o século XIX. Ainda assim, o fato de Herder ter exercido importante influência sobre Gobineau (Boissel, 1967: 40) testemunha o parentesco entre as duas formas de pensamento.

\section{Referências bibliográficas}

ARAÚJO, Ricardo Benzaquen de. Guerra e paz: Casa-grande \& senzala e a obra de Gilberto Freyre nos anos 30. São Paulo: Ed. 34, 1994.

AZEVEDO, Thales de. Gilberto Freyre e a reinterpretação do mestiço. In: Gilberto Freyre, sua ciência, sua arte: ensaios sobre o autor de Casa-grande \& senzala e sua influência na moderna cultura do Brasil, comemorativo do $25^{\circ}$ aniversário da publicação desse seu livro. Rio de Janeiro: José Olympio, 1962.

BOAS, Franz. Race, language, and culture. Chicago/London: The University of Chicago Press, 1982.

BOCAYUVA, Helena. Erotismo à brasileira: o excesso sexual na obra de Gilberto Freyre. Rio de Janeiro: Garamond, 2001.

BOISSEL, Jean. Gobineau polémiste: les races et la république, introduction à una lecture de l'Essai sur l'inégalité des races humaines et
2. Como não há tradução desta obra para o português, todos os excertos transcritos foram traduzidos por mim.

3. Essa ideia foi inspirada pelo conceito de episteme desenvolvido por Michel Foucault em seu clássico As palavras e as coisas, muito embora o termo seja usado aqui em acepção mais circunscrita. Cf. Foucault, 1992.

choix de textes. Utrecht: Jean-Jacques Pauvert, 1967.

BOULOS JÚNIOR, Alfredo. África, africanos e o brasileiro em Casa-grande \& senzala de Gilberto Freyre. São Paulo, 2001. 108 f. Dissertação (Mestrado em História Social - Universidade de São Paulo).

CANDIDO, Antonio. Gilberto Freyre crítico literário. In: Gilberto Freyre, sua ciência, sua arte: ensaios sobre o autor de Casa-grande \& senzala e sua influência na moderna cultura do Brasil, comemorativo do $25^{\circ}$ aniversário da publicação desse seu livro. Rio de Janeiro: José Olympio, 1962.

ELIAS, Norbert. O processo civilizador: uma história dos costumes. Rio de Janeiro: Jorge Zahar Editor, 1990.

FERNANDES, Florestan. $A$ integração do negro na sociedade de classes. São Paulo: Dominus Editora/Editora da Universidade de São Paulo, 1965. 2 v. 
FOUCAULT, Michel. As palavras e as coisas. $6^{\mathrm{a}}$ ed. São Paulo: Martins Fontes, 1992.

FREYRE, Gilberto. Casa-grande E senzala: formação da família brasileira sob o regime da economia patriarcal. [1933] 23 ${ }^{\mathrm{a}}$ ed. Rio de Janeiro: Livraria José Olympio Editora, 1984.

GAHYVA, Helga da Cunha. A epopeia da decadência: um estudo sobre o Essai sur l'inégalité des races humaines (1853-1855), de Arthur de Gobineau. Mana: Estudos de Antropologia Social. Rio de Janeiro: Museu Nacional/UFRJ, v. 17, n. 3, p. 501-518, dez. 2011.

GOBINEAU, M. Arthur de. Essai sur l'inegalité des races humaines. Paris: Librairie de Firmin Didot Frères, 1853, v. 1. Disponível em: <http://gallica.bnf.fr/ark:/12148/ btvlb86266802>. Acesso em: 10/05/2013.

LIMA, Luiz Costa. A versão solar do patriarcalismo: Casa-grande $\mathcal{E}$ senzala. In: $A$ aguarrás do tempo: estudos sobre a narrativa. Rio de Janeiro: Rocco, 1989, p. 187-236.

NABUCO, Joaquim. O abolicionismo. Petrópolis: Vozes, 2012. (Vozes de Bolso)

PALLARES-BURKE, Maria Lúcia Garcia. Gilberto Freyre: um vitoriano dos trópicos. São Paulo: Editora Unesp, 2005.

POLIAKOV, Léon. $O$ mito ariano: ensaios sobre as fontes do racismo e dos nacionalismos. São Paulo: Perspectiva/Editora da Universidade de São Paulo, 1974.

PRATT, Mary Louise. Os olhos do império: relatos de viagem e transculturação. Bauru: Edusc, 1999.
RAEDERS, Georges. $O$ inimigo cordial do Brasil: o Conde de Gobineau no Brasil. Trad. Rosa Freire d'Aguiar. Rio de Janeiro: Paz e Terra, 1988.

RODRIGUES, Raimundo Nina. Mestiçagem, degenerescência e crime. História, Ciências, Saúde - Manguinhos. Rio de Janeiro: Casa de Oswaldo Cruz, v. 15, n. 4, p. 1151-1181, out.-dez. 2008. Disponível em: $<$ http://www.scielo.br/scielo.php?script $=$ sci arttext\&pid $=$ S0104-597020080004000 14>. Acesso em: 25 jul. 2013.

SCHWARCZ, Lilia Moritz. O espetáculo das raças: cientistas, instituições e questão racial no Brasil, 1870-1930. São Paulo: Companhia das Letras, 1993.

SKIDMORE, Thomas E. Preto no branco: raça e nacionalidade no pensamento brasileiro. Rio de Janeiro: Paz e Terra, 1976.

STOCKING JR., George W. Race, culture and evolution: essays in the history of anthropology. Chicago/London: The University of Chicago Press, 1982.

WESTPHALEN, Cecília Maria. A mulher no universo de Casa-grande $\mathcal{E}$ senzala. In: QUINTAS, Fátima (org.). Anais do Seminário Internacional Novo Mundo nos Trópicos. Recife: Fundação Gilberto Freyre, 2001, p. 79-83.

YOUNG, Robert. Colonial desire: hybridity in theory, culture and race. Londres/Nova York: Routledge, 1995.

\section{Resumo}

Casa-grande $\mathcal{E}$ senzala, de Gilberto Freyre, consolidou na cultura nacional a valorização da mestiçagem racial como um dos mais sólidos fundamentos da sociedade brasileira. Este artigo empreende uma releitura da tese freyreana da 
miscigenação, identificando-a como resultado de uma relação erotizada marcada pelo sadismo dos brancos e pelo masoquismo dos negros. Essa noção será comparada com as teses lançadas por Arthur de Gobineau em seu Ensaio sobre a desigualdade das raças humanas (1853-1855), evidenciando os afastamentos e semelhanças que unem a obra freyreana a um importante representante do pensamento racialista.

Palavras-chave: Gilberto Freyre; mestiçagem; racialismo; Gobineau; Casa-grande $\mathcal{E}$ senzala

\begin{abstract}
Slaves $\mathcal{E}$ masters, by Gilberto Freyre, has established in Brazilian culture a positive view of racial miscigenation as one of the bases of the nation's stability and distinctiveness. This paper aims to reevaluate Freyre's theory of hybridity, showing how it results from an eroticized relation characterized by the sadism of whites and the masochism of blacks. This idea can be compared to Arthur de Gobineau's theses presented in his Essay on the inequality of human races (1853-1855), shedding light on the way Freyre's work is ambiguosly connected to an important representative of racialist thought. Keywords: Gilberto Freyre; hybridity; racialist thought; Gobineau; Slaves $\mathcal{E}$ masters.

Résumé

Maîtres et esclaves, de Gilberto Freyre, a mis en place une valorisation du métissage racial comme l'une des bases les plus solides de la culture brésilienne. Cet article propose une nouvelle interprétation de la théorie freyrienne de l'hibridisme, en montrant comme le mélange des races résulte d'un sadisme sexuel des blancs e d'un masochisme des noirs. Cette idée peut être comparée aux thèses présentées par Arthur de Gobineau dans son Essai sur l'inégalité des races humaines (1853-1855), montrant les liens ambigus entre l'œuvre freyrienne et un important représentant de la pensée racialiste. Mots-clés: Gilberto Freyre, métissage, racialisme, Gobineau, Maîtres et esclaves.
\end{abstract}

